\title{
Reproductive Health Policy in China: A Study of Preconception Care in Rural China
}

\author{
Fuqin Liu*
}

\begin{abstract}
Objectives: Policy plays an important role in shaping preconception health and care. The purpose of this study was to explore how preconception care was defined in Chinese government policies. The specific aims of the study were to: (a) define and critically analyze the language of preconception care in the context of Chinese government policies and (b) explore rural women's and healthcare providers' views on preconception care-related government policies.

Materials and Methods: This was a cross-sectional study of Chinese preconception health and care-related policy at the national and provincial levels. The study included an analysis of publicly available preconception care policies issued before August 2009. In addition, individual interviews with rural women and healthcare providers were conducted from April 2009 to August 2009 in Tonglu County, Zhejiang Province, China.

Results: Three major discourses in relation to defining preconception care were identified from the policy documents: (a) preconception care in relation to women's physiology, (b) preconception in relation to marriage registration, and (c) preconception care in relation to being married. Although participants recognized the governmental policy effort in relation to preconception health promotion, they still see policy as a formality.

Conclusion: This was the first study to examine language use in Chinese preconception care policies. The study found that the concept of preconception care was constructed mainly around marriage and that the public views these policies as a formality. Strategic plans are needed to increase societal awareness of the importance of preconception health policies in China.

Keywords: Reproduction, Health, Preconception Care, Policy, Rural China
\end{abstract}

\section{Introduction}

As countries strive for better maternal and child health outcomes, the concept of preconception health has demonstrated increasing global importance in policy agendas (1-3). Preconception health relates to women's health, reproductive freedom, and pregnancy outcomes (3) and includes three major concepts of preconception care: reducing risk in preparation for pregnancy, managing preexisting medical conditions, and delivering preventive interventions (2). In 2006, the United States (U.S.) Centers for Disease Control and Prevention (CDC) issued 10 recommendations for preconception care. These recommendations focus on risk factors and risk reduction and reflect a biomedicine-oriented discourse that dominates the preconception care policy language in the U.S. (4-6). In the same year, preconception care was defined as "as a set of interventions that aim to identify and modify biomedical, behavioral, and social risks to a woman's health or pregnancy outcome through prevention and management, emphasizing those factors which must be acted on before conception or early in pregnancy to have maximal impact" (5).
This definition of preconception care was based on sufficient evidence (5); however, Russell et al. (7) argue that it is not enough to discuss healthcare policy-making in the dominant discourse of evidence-based medicine only because policy-making is the formal struggle over ideas and values. One also needs to address the language, arguments, and discourses in healthcare policy-making. Further, it is important to show the links among policy texts to reveal prevailing ideologies, stories, power relations, and tensions (8) as the public response to a policy may vary. For example, the public's interpretation of the definition of preconception care issued by the U.S. CDC in 2006 was divided. Some groups perceived the definition as an erosion of reproductive choices for individual women because preconception care was defined at the population level. Other groups welcomed the definition because they viewed it as a policy-level effort to improve the health of reproductive-aged women (9). Thus, it is important to have an understanding of preconception health and care policy language and public-level discourses.

Although it is known that preconception care policies still vary by region as related to each region's healthcare sys- 
tem and economic level $(3,10)$ preconception care policy research in developing countries is lacking. What is also known is that many developing countries, as they shape preconception health and care policies, adopt practice recommendations from developed countries (3). An examination of preconception policies in a non-Westernbased society contributes to the ongoing discussion of global preconception health and care. This study investigates the preconception health and care policy agendas and their public responses in China. The specific aims of the study were to (a) define and critically analyze the language of preconception care in the context of Chinese government policies and (b) explore rural women's and healthcare providers' views on preconception care-related government policies.

The Chinese health system has achieved enormous improvements in health and health care, and there has been a dramatic drop in infant mortality since 1949 (11). Rudan et al. (12) reported that the mortality rates for neonates from 1990 to 2008 decreased by $70 \%$ (from 34.0 to 10.2 per 1000 live births). Factors such as nutrition, hygiene, education, living standards, and even cultural changes have contributed to this change in health status (13). Since the 1980s, as a result of a series of new governmental policies, China experienced a fundamental societal transformation.

The government's policy efforts marked the beginning of a reform era in China, one that included the privatization of health care. Subsequently, policies in regard to healthcare services went through two major changes. First, the healthcare financing structure shifted a substantial share of payment from the central government to individual consumers $(13,14)$, which meant that the proportion of out-of-pocket payments increased, which had a noticeable impact on rural populations. The Cooperative Medical System, a form of community-based health insurance available for the rural population before the reform era has collapsed, and prevention healthcare services have become less available to rural residents $(14,15)$.

Second, to control healthcare costs, the government has imposed tight price regulations on medicine and procedures $(13,14)$. These regulations are believed to stimulate hospitals to use more advanced medical equipment to procure higher fees that are less strictly regulated by health policies (14). Hence, from the providers' perspective, health programs that are purely health promotion motivated tend to be secondary. Preconception health promotion is situated with competing interests among the healthcare providers given these issues. Thus, it is important to examine a wide range of policies that have preconception care implications in Chinese contexts.

A well-known preconception care policy endeavor by the Chinese government is the requirement of a health examination before marriage registration, also known as the premarital health examination. Until October 2003, when the examination became voluntary, this health examination was mandated for couples who were seeking to obtain legal marriage status (10). Couples took a routine physical examination, laboratory tests, and reproductive health education (16). Although there is speculation by providers that women consider the voluntary nature of the examination as indicative of its lack of importance (10), it remains unclear how the public has responded to this policy shift.

\section{Materials and Methods}

A cross-sectional, exploratory design was used for this study, which was conducted from April 2009 to August 2009 in Zhejiang Province, China. Critical Discourse Analysis (CDA) was used to examine the language use in preconception care-related government policies. CDA is used to document competing or marginalized discourses in policy texts. In addition, public views were sought through individual interviews. The exploration of public responses to preconception health and care policies enables one to ground policies contextually (17).

\section{Setting}

The study setting was Tonglu County, Zhejiang Province, China. China is grouped geographically into urban and rural areas according to the governmental administration system, and further stratification of rural and urban areas exist in rural regions; thus, residents in rural regions also can be divided into rural residents and urban residents (15). Tonglu is a rural county with urban areas. Tonglu County is also a place of considerable socioeconomic diversity, with the latest population census showing 396,900 individuals, of whom 201,700 are male and 195,200 are female (18).

\section{Data Collection \\ Policy}

Policy identification was ongoing. First, the researcher searched government web sites to identify preconception care-related policies. Following the interviews, the researcher used participants' words, such as "free folic acid," to identify other policy documents. Only policies that pertain to rural Zhejiang Province and were still in effect at the time of the study were included for analysis. All policies were issued between 1979 and 2009. A total of 14 policy documents (Table 1) were included for analysis. Twelve documents were nationally issued, and two were issued at the Zhejiang provincial level. All 14 policy documents were retrieved from publicly available government web sites.

\section{Participants}

The study protocol was approved by the University of Washington Institutional Review Board. Participants were recruited through a purposive sampling strategy. Participant interviews were conducted with three groups of study participants: 1) adult daughters, 2) mothers of the interviewed adult daughters, and 3) healthcare providers. All mother and daughter participants were rural residents. Healthcare providers were recruited from three tiers (village, township, and county) of healthcare facilities in Tonglu County. 
Table 1. Summary of the analysis of Chinese government preconception policies

\begin{tabular}{|c|c|c|}
\hline Year & $\begin{array}{l}\text { Revision year } \\
\text { (if applicable) }\end{array}$ & Policy title \\
\hline \multicolumn{3}{|c|}{$\begin{array}{l}\text { National Level } \\
\text { Policies }\end{array}$} \\
\hline 1979 & 2001 & Population and Family Planning Law of the People's Republic of China \\
\hline 1980 & 2001 & Marriage Law of the People's Republic of China \\
\hline 1988 & & Regulations Concerning the Labor Protection of Female Staff and Workers \\
\hline 1990 & & Regulations on Work Prohibited for Female Staff and Workers \\
\hline 1994 & & Law of the People's Republic of China on Maternal and Infant Health Care \\
\hline 2001 & 2004 & Regulations on the Management of Family Planning Services \\
\hline 2007 & & Regulations on Prepregnancy Health Care Services (Trial) \\
\hline 2009 & & 2009 Maternal and Child Health Care and Community Health Work Focus \\
\hline 2009 & & $\begin{array}{l}\text { Opinions of the CPC Central Committee and the State Council on Deepening the Health Care } \\
\text { System Reform }\end{array}$ \\
\hline 2009 & & $\begin{array}{l}\text { Notice of the State Council on Implementation Plan for the Recent Priorities of the Health } \\
\text { Care Reform (2009-2011) }\end{array}$ \\
\hline 2009 & & Initiation of Six Major National Public Health Programs \\
\hline 2009 & & $\begin{array}{l}\text { Management Plan for the Use of Folic Acid Supplementation in Neural Tube Defects } \\
\text { Prevention Program }\end{array}$ \\
\hline \multicolumn{3}{|c|}{$\begin{array}{l}\text { Provincial Level Policies- } \\
\text { Zhejiang Province }\end{array}$} \\
\hline 2008 & & $\begin{array}{l}\text { Recommendations on Implementation of Free Premarital Medical Examination and } \\
\text { Prepregnancy Medical Examination }\end{array}$ \\
\hline 2009 & & Implementation of 13 Major Province-wide Public Health Service Programs \\
\hline
\end{tabular}

\section{Adult daughters}

This study identified adult daughters as important contributors to the impact of preconception health and care policies. The term adult daughter is used in this study to differentiate the population of adult reproductive-age women from other groups, such as teenagers. Adult daughters' views on policies are important because they are potential preconception program recipients.

\section{Maternal mothers}

This study also identified maternal mothers as important contributors to the impact of preconception health and care policies. The term maternal mother in this study is a socially constructed term to specify their relationship with adult daughters. Maternal mothers' views on policies are important because they have lived through various eras of preconception health and care-related policies.

\section{Healthcare providers}

This study also identified healthcare providers as important contributors to the impact of preconception health and care policies. The term healthcare provider in this study includes potential preconception care providers in the Chinese rural healthcare system. Healthcare providers' views on policies are important because they are potential providers of preconception care in the three tiers of the rural healthcare systems. Further, there are challenges to healthcare providers' being able to recommend or provide preconception care to their patients, despite their agreement on the importance of preconception care (2).

A total of 86 participants were recruited and interviewed. The participants consisted of 40 adult daughters, 10 maternal mothers, and 36 healthcare providers. The adult daughters' ages ranged from 20 to 29 years. Of the 40 adult daughters, 10 maternal mothers participated in the interviews. The mothers were 41 to 60 years old. Among the 36 interviewed healthcare providers, 12 were from village-level clinics, 12 were from township-level hospitals, and 12 were from county-level hospitals. All healthcare provider participants were between 20 and 65 years of age. All participants $(\mathrm{N}=86)$, except one, agreed to be tape-recorded during interviews. Participants were asked to mention the names of any preconception health and care-related governmental policies of which they were aware and then to share their viewpoints on these policies. Participants also were asked to share their views on preconception health- and care-related policies in general. Interviews were conducted in Mandarin Chinese, Tonglu dialect, or a mixture of both languages by the researcher, who is fluent in both languages. The audiotapes were transcribed verbatim.

\section{Data analysis}

This study adapted Allan's (19) policy discourse analytical framework for analyzing the texts. The policy analysis focused on deconstructing and linking across texts to reveal discourses that both shape and are shaped by policy, and the interview data analysis focused on the recognition of the role of power and knowledge in policy implementation (7). For policy text, the major analysis processes involved (a) assessing which policy problems were addressed in the policy text and the background of each policy problem, (b) examining how the policy text provided the solutions to the problems, (c) identifying the impact that the policy text indicated to achieve, and (d) reading and rereading of the policy text and identifying discourses that constructed preconception care. Because the interview text was focused only on the participants' perspectives on policies, 
the analysis of the interviews did not consider all text in the transcripts. The analysis focused on those segments of the text that were relevant to the aim of the study, which was participants' awareness and views of preconception health policies.

Both the policy and interview data analysis were conducted in Mandarin Chinese to preserve the original and contextual meanings of the words. The researcher used ATLAS.ti software for data management and coding. To enhance the rigor of the study, a variety of techniques were used, including validation of the researcher's interpretations by a diverse group of experienced health professionals. To ensure accuracy of English translation of the policy text, the researcher searched for an English version of the analyzed policy documents after completing the data analysis. If an English version of a policy document was located from a government web site, the official translation was referenced when citing the policy text.

\section{Results}

The researcher categorized the findings from the analysis of the policy data into three preconception care discourses. These three discourses are preconception care in relation to women's physiology, preconception care in relation to marriage registration, and preconception care in relation to being married. The researcher divided the findings from the interview data according to group, specifically, adult daughters' responses, maternal mothers' responses, and healthcare providers' responses. Key quotes are provided.

\section{Discourses of preconception care}

In relation to women's physiology

The concept of preconception care as defined by women's physiology stems from the policy text that indicates that women are protected from certain areas of work while experiencing their menstrual periods. This work division is seen in the Regulations Concerning the Labor Protection of Female Staff and Workers (1988) policy and the Regulations on Work Prohibited for Female Staff and Workers (1990) policy. The Regulations Concerning the Labor Protection of Female Staff and Workers policy was issued by the State Council. Article 6 of the policy states:

During the menstrual period of female staff and workers, the Units employing them may not arrange for them to engage in Labor at high altitudes, in low temperatures or involving contact with cold water, or Labor involving physical Labor of the third (3rd) degree of intensity as specified by the state.

In response to this policy, the Ministry of Human Resources and Social Security (formerly known as the Ministry of Labor) provided additional detail about the kind of working conditions and the types of work prohibited by issuing the Regulations on Work Prohibited for Female Staff and Workers policy in 1990. The working conditions from which female workers are protected during their menstrual period include physical work in low temperatures or in a high elevation and work that requires a high degree of strength. These working conditions are considered a risk to women's reproductive health. The Regulations on Work Prohibited for Female Staff and Workers policy was reissued in 2007 without any language change.

\section{In relation to marriage registration}

Concern about the health of women and men at the time of marriage registration appears in Chinese policy text as early as 1980. Two national laws, the Marriage Law of the People's Republic of China (1980 and 2001) and the Law of the People's Republic of China on Maternal and Infant Health Care (1994), indicate the importance of a woman's and man's health condition before they obtain their marriage certificate. Both the Marriage Law of the People's Republic of China (Marriage Law) and the Law of the People's Republic of China on Maternal and Infant Health Care (Law on Maternal and Infant Health Care) stipulate the impact of the health status of an individual (woman or man) on obtaining legal permission to get married.

The Law on Maternal and Infant Health Care considers premarital health or health at the time of marriage registration a vital aspect of maternal and child health. The Law on Maternal and Infant Health Care also indicates that the healthcare system, under the auspices of the Ministry of Health, is responsible for providing premarital health services to intending-to-marry women and men. At the same time, the Law on Maternal and Infant Health Care stipulates that county-level health bureaus are accountable for the provision of premarital health services, which include (a) premarital health guidance, (b) premarital health information services, and (c) a premarital health examination. The purpose of conducting a premarital health examination for intending-to-marry couples, according to the Marriage Law, is "to see whether they suffer from any disease that may have an adverse effect on marriage and child-bearing." Part of the premarital health examination includes the identification of conditions that are not recommended for pregnancy. The presence of these conditions in either women or men can be taken as a recommendation for a "delayed marriage" or for "not getting married at all."

Since the change in premarital screening from mandatory to voluntary in 2003, a more recent national policy that contains language on premarital health services emerged. In the 2009 Maternal and Child Health Care and Community Health Work Focus policy, the language emphasizes the provision of premarital health services to couples. At the provincial level, the government issued the Implementation of 13 Major Province-wide Public Health Service Programs policy in 2009. In this provincial-level policy, free premarital health examination financing was briefly mentioned. Specifically, the county level is responsible for financing free premarital health examinations, and the provincial government provides a subsidy. The policy also uses the phrase two free programs to denote premarital health services and prepregnancy health services, both of which are free for couples who register their marriage in the province. 


\section{In relation to being married}

The Regulations on Prepregnancy Health Care Services (Trial) policy issued in 2007 extended the preconception period beyond the point of obtaining a marriage certificate. This national-level policy was issued by the Ministry of Health as part of a set of regulations to improve the health of the population. The policy defined newly married couples as its focus. The status of being married makes a couple eligible to receive a range of health services listed in the Regulations on Prepregnancy Health Care Services (Trial) policy. According to the policy, bundled healthcare services provided to married couples who are not pregnant include health education, reproductive health counseling, health assessment, and health guidance. The policy defines health examination as part of the prepregnancy health services available to couples and considers its provision as a continuation of the premarital health service provision. The policy also states that the principle of voluntary participation should be followed.

The prepregnancy health message for married couples also is seen in two provincially-issued policy documents: the Implementation of 13 Major Province-wide Public Health Service Programs policy (2009) and the Recommendations on Implementation of Free Premarital Medical Examination and Prepregnancy Medical Examination policy (2008). Although the Recommendations on Implementation of Free Premarital Medical Examination and Prepregnancy Medical Examination policy states that the targeted population is newly-married couples and couples who have obtained governmental permission to give birth, the policy defines the availability of the free health examination service as limited to women and as having an emphasis on improving birth outcomes for rural population.

The messages about the provision of free health examination to promote better birth outcomes in both these provincial-level policies are consistent with the messages outlined in two main family planning related policies. The first one is the Population and Family Law of the People's Republic of China policy (1979 and 2001), also known as the Family Planning Law. The second one is the Regulations on the Management of Family Planning Services policy (2001 and 2004). The main preconception care goal of the family planning related policies is to establish premarital healthcare policies as a means to decrease birth defects and to improve the health of newborns. The need to provide free prevention oriented reproductive health services for married couples is also recognized in the most recent family planning policies. According to the Regulations on Management of Family Planning Services policy, rural couples who practice family planning are eligible to receive free basic family planning services, such as contraceptives. These policies are clear on one message that strengthening family planning, especially among rural married couples, is a national priority.

Additionally, two main messages are identified in government polices with regard to married women's care as part of preconception care. One message concerns the work environment for married women who are planning to be- come pregnant, and the other message is in regard to folic acid supplementation for married women who are planning to become pregnant. The message on a list of protected work conditions for married women who are planning to get pregnant is similar to the message for women who are experiencing their menstrual period, as both are outlined in the Regulations Concerning the Labor Protection of Female Staff and Workers (1988) policy, and the Regulations on Work Prohibited for Female Staff and Workers (1990) policy. Folic acid supplementation for married women who are planning to become pregnant appeared in three national- and one provincial-level policy documents. These policies are the Initiation of Six Major $\mathrm{Na}$ tional Public Health Programs (2009), Maternal and Child Health Care and Community Health Work Focus (2009), Management Plan for the Use of Folic Acid Supplementation in Neural Tube Defects Prevention Program (2009), and the Implementation of 13 Major Province-wide Public Health Service Programs (2009). These policies stated that the recommendation for folic acid supplementation is a daily dose of $0.4 \mathrm{mg}$ to begin three months before conception and to continue through the first three months of pregnancy.

The provision of free folic acid for rural women to decrease the incidence of neural tube defects was the key message in the Management Plan for the Use of Folic Acid Supplementation in Neural Tube Defects Prevention Program policy. The national policy also states that the central Chinese government will provide subsidies to finance the free folic acid program for rural women, while the responsibility of program implementation rests upon each province, region, or municipality. The key message in these three national- and one provincial-level policies is that rural women receive folic acid as a part of preconception care to improve birth outcomes. Two national policies set the stage for including rural married women who are planning to get pregnant on policy agenda. These two policies are the Opinions of the CPC Central Committee and the State Council on Deepening the Health Care System Reform (2009) and the Notice of the State Council on Implementation Plan for the Recent Priorities of the Health Care Reform (2009-2011) (2009). These two national policies focused on pressing issues pertaining to rural people.

\section{Public responses to policies}

Adult daughters' responses

Only five adult daughters reported that they were aware of any governmental policies in relation to preconception care. Ten participants reported that they had seen at least one kind of preconception-related educational material placed in public places but did not remember the content. A total of 30 participants stated that they would pay more attention to governmental messages after they got married. Ten participants stated that a premarital health examination is not necessary. For example, one participant said: I heard people say there is a premarital health examination before you register, but they say you don't have to go. A while ago, I asked a classmate of mine, "What do you have 
to get examined before you register?" She told me it does not matter if you don't go; it's not important. (A27) Of the adult daughter participants, 35 stated that their decision to support or disregard a preconception care-related policy depends on the benefits. For example, one participant stated, "If I think it is not beneficial or not directly related to me, I won't respond to the policy" (A13). Three participants, however, stated that they would not seek governmental resources even if the policy is well-intended. For instance, one participant said, "I think care before one gets pregnant is something personal. I don't like to talk personal things for others to hear or seek out resources provided by the government. Even if the policy is good, I don't like to go" (A26).

A "lack of standardization" and "lack of details" of the current preconception health examinations were voiced as the major hindrance to adult daughters' engagement in policies. The fee for health services was not a major concern for the adult daughters. For example, one participant said, "If they do the examination sincerely, it's not a problem to pay a few hundred yuan. I won't go for those disorganized and perfunctory exams" (A19).

Among the six married adult daughter participants, four said they had a premarital health examination. One of the four participants stated that she already was pregnant at the time of her premarital health examination. When asked whether the premarital health examination has anything to do with having a healthy baby, 32 unmarried adult daughters stated, "Yes." However, among the four married adult daughters who had the premarital health examination, only two stated, "Yes." Although their views of the effectiveness of the premarital health examination varied, 31 out of the 34 unmarried adult daughters indicated that they would go for a premarital health examination.

\section{Maternal mothers' responses}

Only two maternal mothers reported that they were aware of any governmental policies in relation to preconception care. The major obstacles for knowing about the policies were "not going out," "working in the factory every day," and "not having time for getting to know policies." For example, one participant said, "I stay at home every day, so I seldom hear anything about the policies that the government hands down" (B16). Seven participants stated that, if they heard of any preconception care-related policies, they would share the message with their daughters. However, three participants indicated that they would tell the policy message to their daughters only after a confirmed wedding date. Three participants said that they would support whatever preconception health and care policies that the government issues.

\section{Healthcare providers' responses}

A total of 27 healthcare providers stated that they had heard of policy messages on preconception care, while 12 participants said that they do not pay attention to preconception care-related policies because they are not within the scope of their practice. Only four participants stated that preconception care was within the scope of their practice. Seven participants pointed out that "village women's officers" played important roles in implementing the current preconception care models defined by government policies.

Major concerns identified by the participants in regard to preconception care-related governmental policies were "the change of premarital health examination from mandatory to voluntary by the government," "there is no commensurate reimbursement for performing the premarital health examination," "it's too much of a formality," and "insufficient public awareness." For example, one participant said, "Some policy messages from above are not very realistic; they are just a formality" (CT9). Another participant stated:

Those officials who make policy often go to differ-

ent places around the world to exchange ideas with

their counterparts. After some Western ideas were accepted, they were stuck in those policies. However, there is still a gap between us and the West in terms of social foundation. Some of the policies are first accepted by health providers and then later by the ordinary people. (CT7)

Three participants described the response to policies in the rural healthcare system and among healthcare providers as "being perfunctory." The use of flyers or bulletin boards to educate the public about preconception health was viewed as an ineffective method. A total of 14 participants said that "more aggressive propaganda" was needed to "raise public awareness."

Although preconception care was not within the current scope of practice of the majority $(\mathrm{N}=32)$ of healthcare provider participants, when asked under which conditions they would be more responsive to the governmental policy messages, 13 participants said that they would support the policies without hesitation. The reasons, however, represented a range of responses, including "policies must be well-intended," "if it is required," "because it is our duty," and "because it will be audited." Participants identified the financing of preconception care as a major means to optimize the impact of policy. Four village-level participants stated that proper reimbursement was an important factor for them. One participant stated, "It is now a market economy. If they tell us to go do something, they should first take out the money" (CV11). Another participant said:

If the government orders us to do it, we will definitely comply. We will do what the government tells us to do. But, of course, we will be more motivated if there is certain reimbursement. This is an era of market economy. That's the reality. This is not just my view; everyone is this way now. (CV6)

When asked whether there were discrepancies between what the government prescribes and what people believe, one county-level healthcare provider stated that the current preconception care policy message was in line with what people think, and three participants voiced the need for the government to make the premarital health examination a mandatory requirement, particularly in view of 
their observing an increasing number of pregnant brides. The reasons described were "mistaken as unimportant," "considered troublesome even when it is free," and "the public awareness varies." Healthcare provider participants did not see themselves as effective as they were expected to be. In this regard, one provider stated:

The government should first issue policies to make them have premarital health examination, attend health education class, etc. We cannot be too successful if we, as healthcare providers, are the only people tell them to have preconception care. I don't think too many people would respond. (CV4)

\section{Discussion}

Although the preconception care effort in China primarily involved a premarital health examination (10), this study found that the Chinese government has promulgated a multidirectional policy effort in the last 30 years with regard to preconception health promotion and care activities. The 14 policy documents in this study covered a variety of preconception health- and care-related issues that also are seen in the international setting (1-3). This study also showed that a more intense preconception care policy effort was initiated in China in the last few years at both the national and provincial level.

By examining the language of preconception health and care-related policies, the researcher found that preconception care policy language is constructed mainly around marriage. Although women are still in the center of the preconception care conceptualization, men are integrally connected with women in Chinese preconception care policies. A couple's preconception health condition can be determined by a premarital health examination and a prepregnancy health examination. Legally married couples can utilize certain free reproductive health services, such as the receipt of free contraceptives. Because the construction of preconception care in Chinese policies centers around marriage, the inclusion of men in preconception care can be traced back to the 1970s, as compared to the relatively new inclusion of men in the U.S. setting (3).

Further, this study also found that the preconception health and care policy language of the Chinese government, both at national and provincial levels, has mainly a biomedicine focus, similar to the dominant preconception health and care policy languages in international settings (6). However, the Chinese preconception care policies also contain a nonbiomedical message that is constructed around menstrual care. The idea of menstrual care in relation to preconception health has not been reported in the literature. This finding calls for further study of the Chinese conceptualization of women's health, especially in relation to the connection between menstrual care and pregnancy outcomes.

Through an exploration of participants' responses to preconception health and care-related policies, this study found that participants had diverse viewpoints about well-intended policies. These viewpoints, however, were not centered on the debate about the control of repro- ductive choices for individuals, as reported by Atrash et al. (2). Rather, they speak of the public perception of the policies as a formality. The view that Chinese political discourse is formalistic is seen in Schoenhals' (20) work on formalized language in contemporary Chinese politics. Seeing policy as a formality poses a challenge for the implementation of current preconception care policies. As a result, free preconception health services will continue to be underutilized, as expressed by the healthcare providers in this study.

Contrary to the health financing structure shift among other types of healthcare services $(13,14)$ the cost of major preconception care services in rural China is absorbed by governmental funds. Nonetheless, the public remains skeptical about the government policy effort in regard to the provision of free preconception health services. The concern about the quality of these free health services indicates a lack of confidence in the existing health system. This finding expands the discourse of uneven quality of care, as identified by Hu et al. (21) as one of the major setbacks to China's rural healthcare reform. Wang et al. (22) emphasized the importance of changing attitudes toward premarital screening to increase participation in the premarital screening program. In addition, the results of the current study indicated that the public's perception of policy affects their attitude toward preventive screening. With the rapid socioeconomic changes and the growing public demand for quality health care, Chinese policymakers need to revisit the current policy agenda to address the diversifying preconception health and care needs.

\section{Conclusion}

As countries strive for better maternal and child health outcomes, preconception health has become an integral part of policy agendas. Policies are needed to guide best preconception care practice and research. An inspection of preconception care policies in China and the rural Chinese public's response to these policies yielded several important implications for global health. First, public response is an important aspect of the evaluation of the impact of a policy. This study shows that preconception care policies are being formulated and revised by the Chinese government with a focus on the provision of free health services; however, the awareness, or utilization of the nocost health services, was not high by the adult women interviewed in this study. Innovative strategies are needed to raise public awareness of preconception health and care. Second, policy discourses require careful examination at various levels. Language use in policy implementation is as important as it is in policy formulation. Different interests operate at the policy formulation stage and the policy implementation stage. This study shows that the Chinese central government is responsible for setting the policy directions, while local governments absorb the cost for most free preconception care services. Thus, prevention-oriented preconception care services compete with many other interests at the local government levels. Implementation policies at local levels or clinical guidelines reflect the 
amount of resources and funds allocated to the preventive-oriented preconception care services. The concern about the funding for preventive service is not unique to the Chinese context.

Finally, policies can be at risk of being considered a formality. Although the view that Chinese political discourse is formalistic was reported in the literature (20), as evidenced by the participants, women were not convinced of the worth of the preconception care policy efforts in terms of their health and well-being. Future preconception care policymaking should solicit input from a variety of stakeholders, including consumers.

\section{Ethical issues}

The study was approved by the University of Washington Institutional Review Board, USA.

\section{Conflict of interests}

The author has no conflicts of interests to disclose.

\section{Acknowledgments}

I would like to thank the following people at the University of Washington: Dr. Doris Boutain and Dr. Nancy Fugate Woods from School of Nursing, Dr. Stevan Harrell from the Department of Anthropology, and Dr. Dongsheng Zang from School of Law for their mentorship and guidance throughout this study. I also would like to thank Dr. Judith McFarlane, Dr. Donna Scott Tilley, and Dr. Vicki Zeigler at Texas Woman's University for providing comments on the manuscript.

\section{References}

1. Atrash HK, Johnson K, Adams M, Cordero JF, Howse J. Preconception care for improving perinatal outcomes: the time to act. Matern Child Health J 2006;10(5 Suppl): S3-11.

2. Atrash H, Jack BW, Johnson K, Coonrod DV, Moos. MK, Stubblefield PG, et al. Where is the "W"oman in MCH? Am J Obstet Gynecol 2008;199(6 Suppl): S25965.

3. Boulet SL, Parker C, Atrash H. Preconception care in international settings. Matern Child Health J 2006;10(5 Suppl):S29-35.

4. Berghella V, Buchanan E, Pereira L, Baxter JK. Preconception care. Obstet Gynecol Surv 2010;65(2):119-31.

5. Johnson K, Posner SF, Biermann J, Cordero JF, Atrash HK, Parkek CS, et al. Recommendations to improve preconception health and health care--United States. A report of the CDC/ATSDR Preconception Care Work Group and the Select Panel on Preconception Care. MMWR Recomm Rep 2006;55(RR-6):1-23.

6. Posner SF, Johnson K, Parker C, Atrash H, Biermann
J. The national summit on preconception care: a summary of concepts and recommendations. Matern Child Health J 2006;10(5 Suppl):S197-205.

7. Russell J, Greenhalgh T, Byrne E, McDonnell J. Recognizing rhetoric in health care policy analysis. J Health Serv Res Policy 2008;13(1):40-6.

8. Shaw SE, Greenhalgh T. Best research - for what? Best health - for whom? A critical exploration of primary care research using discourse analysis. Soc Sci Med 2008;66(12): 2506-19.

9. Curtis MG. Preconception care: a clinical case of "think globally, act locally”. Am J Obstet Gynecol 2008;199(6 Suppl):S257-58.

10. Ebrahim SH, Lo SS, Zhuo J, Han JY, Delvoye P, Zhu L. Models of preconception care implementation in selected countries. Matern Child Health J 2006;10(5 Suppl):S37-42.

11. Blumenthal D, Hsiao W. Privatization and its discontents - the evolving Chinese health care system. N Engl J Med 2005;353(11):1165-70.

12. Rudan I, Chan KY, Zhang JS, Theodoratou E, Feng $\mathrm{XL}$, Salomon JA, et al. Causes of deaths in children younger than 5 years in China in 2008. Lancet 2010;375(9720):1083-9.

13. Ma S, Sood N. A comparison of the health systems in China and India. RAND Center for Asian Pacific Policy; 2008.

14. Ma J, Lu M, Quan H. From a national, centrally planned health system to a system based on the market: lessons from China. Health Aff (Millwood) 2008;27(4):937-48.

15. Liu M, Zhang Q, Lu M, Kwon CS, Quan H. Rural and urban disparity in health services utilization in China. Med Care 2007;45(8):767-74.

16. Hesketh T. Getting married in China: pass the medical first. BMJ 2003;326(7383):277-9.

17. Lejano RP. Frameworks for policy analysis: merging text and context. New York: Routledge; 2006.

18. Jin RB. Zhejiang Statistical Year Book 2007. China Statistics Press; 2007.

19. Allan EJ. Policy discourses, gender, and education: constructing women's status. New York: Routledge; 2008.

20. Schoenhals M. Doing things with words in Chinese politics: five studies. Berkeley: Center for Chinese Studies, Institute of East Asian Studies, University of California; 1992.

21. Hu S, Tang S, Liu Y, Zhao Y, Escobar ML, de Ferranti D. Reform of how health care is paid for in China: challenges and opportunities. Lancet 2008;372(9652):1846-53.

22. Wang P, Wang X, Fang M, Vander Weele TJ. Factors influencing the decision to participate in medical premarital examinations in Hubei Province, MidChina. BMC Public Health 2013;13:1-7.

Copyright (C) 2014 The Author(s); This is an open-access article distributed under the terms of the Creative Commons Attribution License (http://creativecommons.org/licenses/by/4.0), which permits unrestricted use, distribution, and reproduction in any medium, provided the original work is properly cited. 